\title{
Covalent attachment of a bioactive hyperbranched polymeric layer to titanium surface for the biomimetic growth of calcium phosphates
}

\author{
D. Tsiourvas $\cdot$ A. Tsetsekou $\cdot$ M. Arkas • \\ S. Diplas $\cdot$ E. Mastrogianni
}

Received: 7 June 2010/Accepted: 25 October 2010/Published online: 11 November 2010

(C) The Author(s) 2010. This article is published with open access at Springerlink.com

\begin{abstract}
This work is investigating the chemical grafting on Ti surface of a polymer/calcium phosphate coating of improved adhesion for enhanced bioactivity. For this purpose, a whole new methodology was developed based on covalently attaching a hyperbranched poly(ethylene imine) layer on Ti surface able to promote calcium phosphate formation in a next deposition stage. This was achieved through an intermediate surface silanization step. The research included optimization both of the reaction conditions for covalently grafting the intermediate organosilicon and the subsequent hyperbranched poly(ethylene imine) layers, as well as of the conditions for the mechanical and chemical pretreatment of Ti surface before coating. The reaction steps were monitored employing FTIR and XPS analyses, whereas the surface morphology and structure of the successive coating layers were studied by SEM combined with EDS. The analysis confirmed the successful grafting of the hybrid layer which demonstrated
\end{abstract}

D. Tsiourvas · M. Arkas

Institute of Physical Chemistry, NCSR "Demokritos",

15310 Aghia Paraskevi, Attiki, Greece

A. Tsetsekou $(\bowtie) \cdot$ E. Mastrogianni

School of Mining Engineering and Metallurgy,

National Technical University of Athens, Iroon Polytechniou,

Zografou Campus, 15780 Athens, Greece

e-mail: athtse@metal.ntua.gr

S. Diplas

SINTEF Materials and Chemistry, Forskningsvn 1,

NO-0314 Oslo, Norway

S. Diplas

Department of Chemistry and Centre for Materials Science

and Nanotechnology (SMN), University of Oslo,

P.O. Box 1033, Blindern NO-0315 Oslo, Norway very good ability for hydroxyapatite growth in simulated body fluid.

\section{Introduction}

The development of bioactive and biocompatible surfaces as building blocks for biomaterial construction has recently drawn much attention [1]. In this context titanium, a very promising biocompatible material, is extensively used in dentistry for manufacturing dental implants and in orthopedics for bone-anchoring systems [2, 3]. Its surface chemistry and structure are prime factors governing bone integration [4]. However titanium and its alloys are bioinert and when they are used for osseointegration a fibrous tissue of variable thickness may form encapsulating and isolating the implants from the surrounding environment [5-7].

In order to further improve the biocompatibility and applicability of titanium a bioactive layer should be produced. For this purpose, many physical and chemical surface modification processes have been implemented such as plasma spraying, dip coating, chemical vapor deposition and electrophoresis [7-11] in order to cover titanium surface with ceramics such as bioglass glass-ceramics and especially hydroxyapatite [12-14] as these materials can bond directly to living bone or tooth when used as replacement materials. However, the coatings developed to date have not led to the expected results, mostly due to the lack of surface tailoring for efficient osseointegration coupled with inefficient coating adhesion to the implant surface and non-uniformity across the thickness of the coating $[15,16]$.

Similarities of hydroxyapatite to natural bone or tooth in structure, crystal size, as well as proper control of composition, crystallinity and surface area, during the coating 
process, are crucial factors for the functionality of the composite structures. Biologically mineralized apatite crystals are typically formed in an organic matrix with precise regulation of synthetic mechanism through proteins that play a key role in templating the structure of bone tissue. In order to synthetically prepare apatite having the same crystal structure and dimensions as in bones, biomimetic routes have been developed employing polymers such as monosaccharides [17] and related polymers $[18,19]$ or more recently dendrimers [20-25] to modulate crystal nucleation and growth.

The most critical stage in biomimetic synthesis involves the utilization of macromolecules having shape and dimensions analogous to those of proteins and bearing functional groups capable of producing a biosynthetic effect similar to that of the proteins in a living organism. Therefore, for the biomimetic synthesis of hydroxyapatite a large number of natural and synthetic polymers has been investigated. Among them, dendrimers and hyperbranched polymers (collectively referred to as dendritic polymers) are very promising candidates as artificial proteins since they have a three-dimensional well defined chemical structure, similar size and weight [26] and can also have positive, or negative, charged surfaces.

One of the most challenging aspects of this technique is that the biomimetic polymer could be stably bound to the surface through chemical bonds that are not susceptible to chemical cleavage by substances present in the biological milieu (e.g. enzymes). The scope of the work is to produce a hydroxyapatite layer, with characteristics similar to those of biogenic apatite, firmly attached on the titanium surface. This approach includes surface activation by proper chemical pretreatment, chemical bonding with an appropriately functionalized siloxane polymer intermediate layer and subsequent chemical attachment of hyperbranched poly(ethylene imine) (PEI) that are able to promote the formation, by a so-called biomimetic approach, of a firmly attached calcium phosphate layer. The bioactivity of this layer was evaluated with experiments in simulated body fluid (SBF).

\section{Experimental}

\subsection{Materials}

Hyperbranched poly(ethylene imine), PEI, $(\mathrm{Mn}=5,000)$ was purchased from Hyperpolymers INC. The primary: secondary:tertiary amino groups ratios of PEI (1:1.15:1) was estimated by inverse gated ${ }^{13} \mathrm{C}$ NMR. (3-chloropropyl) triethoxysilane $(>95 \%)$ was purchased from Aldrich and used as received. Ultapure Millipore water was used throughout this study.

\subsection{Ti substrates preparation}

\subsubsection{Ti polishing}

Titanium coupons (cpTi, $1 \mathrm{~mm}$ thickness, Alfa Aesar) were prepared by cutting $10 \times 10 \mathrm{~mm}$ squares and treating their surface mechanically to different polishing levels to assess the effect of surface morphology and roughness on coatings development. For this purpose, three coupon categories with different levels of surface polishing were produced: (a) as received; (b) ground by \#400 to 1,000 grit silicon carbide (SiC) metallographic paper; and (c) ground by \#400 to 4,000 grit $\mathrm{SiC}$ paper followed by final polishing on a polishing cloth (MD Struers) using a colloidal $\mathrm{SiO}_{2}$ $(0.04 \mu \mathrm{m})$ suspension (Struers OP-U). The roughness values obtained (Mahr Perthen Profilometer) for the as treated samples are summarized in Table 1. The as prepared samples were ultrasonically cleaned in successive baths of water, acetone and ethanol for $20 \mathrm{~min}$ each followed by a final ultrasonic washing with water for $10 \mathrm{~min}$.

\subsubsection{Ti chemical pretreatment}

Titanium coupons were subjected to different chemical treatments as follows:

A. Passivation method [27]: Ti coupons were sonicated for $10 \mathrm{~min}$ in each of the following chemicals in succession: acetone ( $70 \%$ by volume), ethanol, and water, respectively. Following sonication in water, the coupons were placed in a 3:7 (v/v) nitric acid-water solution for $30 \mathrm{~min}$ at room temperature. Following this treatment, the samples were rinsed with water and placed in a covered water bath for $24 \mathrm{~h}$.

B. Piranha treatment [27]: The coupons were first sonicated for $30 \mathrm{~min}$ in $70 \%$ isopropyl alcohol. Following sonication, concentrated sulfuric acid was poured into a beaker and $35 \%$ hydrogen peroxide was slowly added to a final 7:3 (v/v) ratio of sulfuric acid to hydrogen peroxide and the resulting mixture was then gently mixed. Coupons were immersed for $10 \mathrm{~min}$ in this solution before being removed and placed in a second, fresh, piranha solution for $5 \mathrm{~min}$. After this period, the metal coupons were rinsed

Table 1 Roughness values of Ti surface after different polishing treatments

\begin{tabular}{lll}
\hline Sample & $\begin{array}{l}\text { Mean roughness, } \\
\mathrm{Ra}(\mu \mathrm{m})\end{array}$ & $\begin{array}{l}\text { Maximum roughness, } \\
\operatorname{Rmax}(\mu \mathrm{m})\end{array}$ \\
\hline As received & $0.44 \pm 0.05$ & $3.78 \pm 0.6$ \\
Polished up to 1,000 grit & $0.18 \pm 0.01$ & $1.40 \pm 0.08$ \\
Fine polished & $0.11 \pm 0.01$ & $0.68 \pm 0.04$ \\
\hline
\end{tabular}


twice with water before being placed in water bath for $24 \mathrm{~h}$.

C. Treatment with alkali solution [28]: Titanium coupons were ultrasonically cleaned in water, acetone, and ethanol for $20 \mathrm{~min}$ each, and finally in water for another $10 \mathrm{~min}$. Subsequently, they were immersed in $5 \mathrm{M} \mathrm{NaOH}$ at $60^{\circ} \mathrm{C}$ for $24 \mathrm{~h}$. After the $24 \mathrm{~h}$ period, the substrate plates were gently washed with water and dried under vacuum.

\subsection{Grafting of PEI and calcium phosphate formation}

Grafting of PEI on chemically pretreated Ti surfaces was performed in a two step process as shown in Scheme 1. During the first reaction step, titanium coupons, treated with $\mathrm{NaOH}$ and thoroughly dried under vacuum, were immersed into (3-chloropropyl)triethoxysilane and allowed to react with the $-\mathrm{O}^{-} \mathrm{Na}^{+}$groups, present on $\mathrm{Ti}$ surface, under argon at room temperature for $24 \mathrm{~h}$. Subsequently, the temperature was raised at $95^{\circ} \mathrm{C}$ for $24 \mathrm{~h}$ to complete the hydrolysis-condensation reactions. Finally, the coupons were repeatedly rinsed with acetonitrile to remove unreacted species and dried under vacuum. For the next reaction step which involves the reaction of the chloropropyl moieties with the tertiary amine groups of hyperbranched PEI, the coupons were immersed into a $10 \%$ wt PEI solution in acetonitrile/methanol $(3: 1 \mathrm{v} / \mathrm{v})$ and allowed to react under argon for $24 \mathrm{~h}$ at $75^{\circ} \mathrm{C}$. Coupons were washed with methanol and dried under vacuum.

Calcium phosphate formation on PEI grafted Ti coupons was carried out by immersing these coupons in $0.1 \mathrm{M}$ $\mathrm{CaCl}_{2}$ solution at $0^{\circ} \mathrm{C}$ and subsequent addition of an equal volume of $0.06 \mathrm{M} \mathrm{Na}_{2} \mathrm{HPO}_{4}$ solution. The reaction vessel was either kept at room temperature for 1 day or hydrothermally treated either at $80^{\circ} \mathrm{C}$ for $16 \mathrm{~h}$ or at $130^{\circ} \mathrm{C}$ for $6 \mathrm{~h}$ in an autoclave (Steroclave, TKA, Italy). Finally, the samples were repeatedly washed with water and allowed to dry under vacuum.

\subsection{Characterization methods}

The successive modifications on titanium surface were monitored by Fourier Transformation Infrared (FTIR) spectroscopy employing a Nicolet 6700 Fourier Transformed Infrared spectrometer equipped with an attenuated total reflectance accessory with diamond crystal (Smart Orbit, Thermo Electron Corporation). Fine polished samples were employed for this purpose and spectra were recorded at $4 \mathrm{~cm}^{-1}$ resolution. Scanning electron microscopy (SEM) (JEOL 6380 LV) combined with Energy Dispersive Microanalysis (EDS, OXFORD INCA ENERGY 250 Premium Resolution $10 \mathrm{~mm}^{2} / 133 \mathrm{eV}, \mathrm{LN}_{2}$ ) were also employed to investigate the morphology and
Scheme 1 Schematic representation of the reaction steps carried out for the development of a chemically attached hyperbranched polymeric layer to alkali treated Ti surface

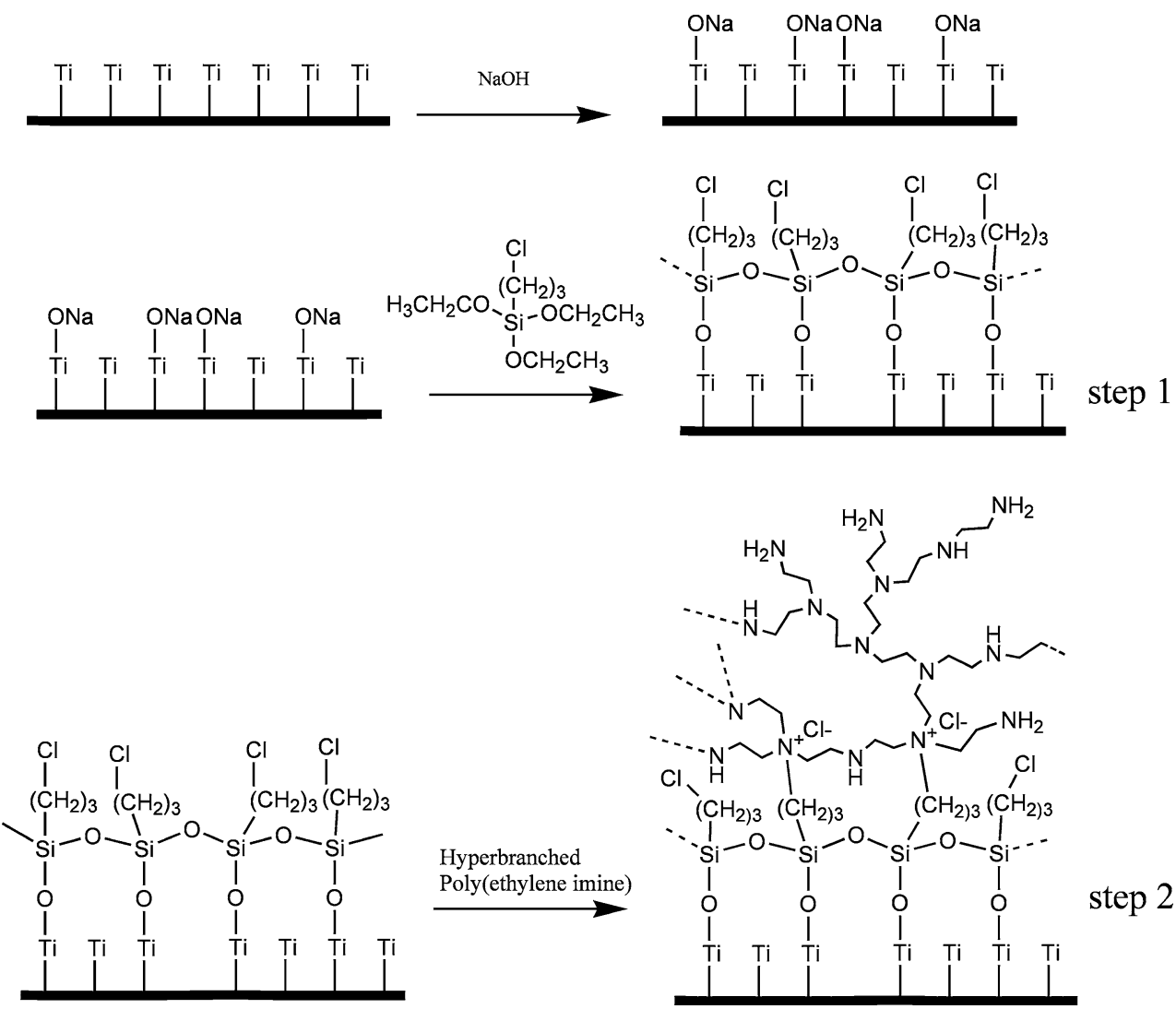


chemical composition of Ti surface after each treatment and coating deposition. Further, $\mathrm{X}$ ray photoelectron spectroscopy (XPS) analysis was performed on fine polished samples in a KRATOS Axis Ultra ${ }^{\text {DLD }}$ using monochromatic $\mathrm{Al} \mathrm{K} \alpha$ radiation $(h v=1,486.6 \mathrm{eV})$. The spectra were acquired at $0^{\circ}$ angle of emission in hybrid mode (i.e. using both electrostatic and magnetic lenses). In hybrid mode the area of analysis is determined by the slot aperture (approx. 700 microns $\times 300$ microns). Both survey and high resolution scans were acquired at pass energies 160 and $20 \mathrm{eV}$, respectively. The analysis was performed under ultra high vacuum conditions with the pressure in the analysis chamber being $10^{-9}$ torr. XPS quantification was performed using KRATOS sensitivity factors and the high resolution scans. Charge compensation was achieved by using low energy electrons from a flood gun and charge correction was done using the Ti2p for pure $\mathrm{Ti}(453.86 \mathrm{eV})$ [29] and $\mathrm{C} 1 \mathrm{~s}$ for $\mathrm{C}-\mathrm{C} / \mathrm{C}-\mathrm{H}$ at $285 \mathrm{eV}$ [30].

\subsection{Evaluation of bioactivity in SBF}

Ti samples, after the various chemical pretreatments employed or after chemically attaching PEI were submerged in an SBF solution to monitor calcium phosphate layer growth and indirectly assess their bioactivity. The Tas-SBF solution (27 $\mathrm{mM} \mathrm{HCO}_{3}^{-}$Tris- $\mathrm{HCl} \mathrm{SBF}$ ), which is considered to favour the formation of calcium phosphate coatings compared to other SBF formulations [31], was selected for this purpose. The different samples examined were kept in Tas-SBF at a constant temperature of $37^{\circ} \mathrm{C}$ and at a $\mathrm{pH}$ value fixed at the physiological value of 7.4 for a period of up to 28 days. The solution was renewed every $48 \mathrm{~h}$ to keep its properties constant during all this period. Monitoring of calcium phosphate formation was made by removing samples from SBF after 1, 3, 5, 7, 14 and 28 days. The morphology and microstructure of deposited layers were analysed by SEM combined with EDS as described in Sect. 2.4 and by X-Ray diffraction (XRD, Siemens D5000, Cu, Ka). Their thickness was also estimated by SEM analysis on cross sectional samples produced via careful sectioning and standard metallographic preparation procedures.

\section{Results and discussion}

\subsection{Chemical pretreatment of $\mathrm{Ti}$}

Covalent attachment of silicon compounds on Ti surface is based on the intrinsic ability of silanol groups to react with the hydroxyl groups present on the oxidized layer of an activated, after appropriate chemical pretreatment, metal surface. Therefore, Ti surface pretreatment is an essential prerequisite for a successful and reproducible silanization. For this purpose, various chemical pretreatments of $\mathrm{Ti}$ surface, as described in the experimental section, were examined. As shown by SEM analysis, $\mathrm{NaOH}$ treatment formed a porous surface layer (Fig. 1a), while EDS analysis (Fig. 1d) revealed the presence of $\mathrm{Na}, \mathrm{Ti}$, and $\mathrm{O}$ atoms (2.7, 35.0 and 62.3 at\%, respectively) confirming the formation of sodium titanate gel layer in accordance with literature $[15,28]$. Other pretreatments such as the

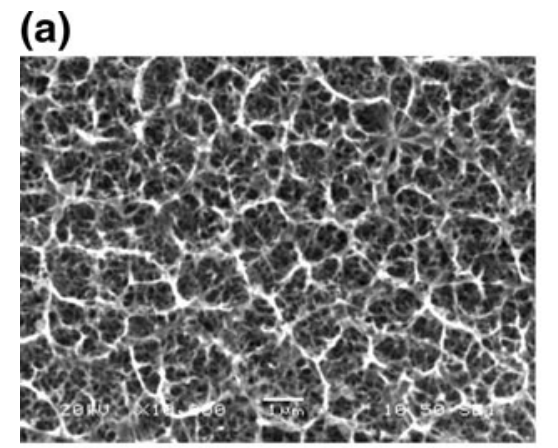

(d)

(b)

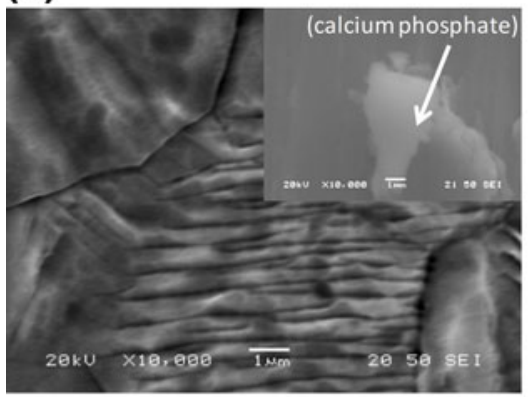

(e)

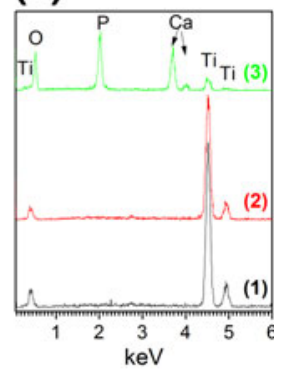

(c)
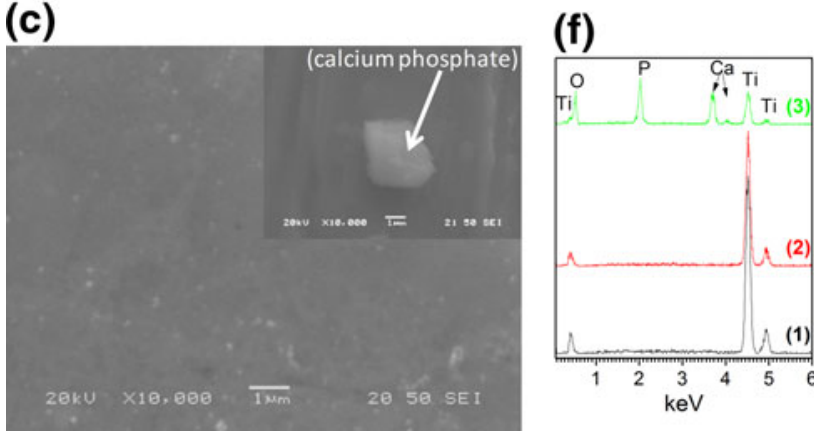

Fig. 1 SEM secondary electron images $(\mathbf{a}, \mathbf{b}, \mathbf{c})$ and respective EDS analysis $(\mathbf{d}, \mathbf{e}, \mathbf{f})$ of fine polished $\mathrm{Ti}$ surface after different chemical pretreatments: (a) $5 \mathrm{M} \mathrm{NaOH}$, (b) piranha and (c) passivation pretreatment. Inserts in images (b) and (c): calcium phosphate grains inhomogeneously distributed on $\mathrm{Ti}$ surface after the respective chemical pretreatment followed by the silanization, PEI grafting, calcium phosphate formation and hydrothermal treatment steps. Lines 1, 2 and 3 in images (e) and (f) correspond to: EDS pattern of Ti surface after the chemical pre-treatment (line 1), EDS pattern of the final surface after coating with calcium phosphate and hydrothermal treatment at $80^{\circ} \mathrm{C}$ (line 2) and $\mathrm{EDS}$ point analysis on calcium phosphate grain (line 3) 
passivation method or the piranha treatment did not give comparable results. In these cases, the surface of Ti did not exhibit the porous network observed after $\mathrm{NaOH}$ treatment (Fig. 1b and c). Furthermore, these two pretreatments did not lead to successful silanization and PEI grafting on the surface and as a result non homogeneous formation of calcium phosphate layers was evidenced by SEM (inserts in Fig. $1 \mathrm{~b}$ and $\mathrm{c}$ ) and EDS (lines 2 and 3 in Fig. 1e and $\mathrm{f}$ ).

\subsection{Ti surface functionalization}

The development of a firmly attached calcium phosphate layer on Ti surface was pursued by chemically attaching a PEI layer on $\mathrm{Ti}$ surface, which is expected to enhance calcium phosphate deposition from SBF due to the intrinsic property of poly(amines) to biomimetically induce hydroxyapatite nanocrystals formation through, basically, electrostatic interactions [19-25]. Grafting of PEI was carried out in two stages (Scheme 1), specifically by first chemically attaching on $\mathrm{Ti}$ surfaces of a trietholyethoxysilane film bearing in addition a functional group, i.e. an alkylchloride moiety, which can, at a second stage, react with PEI.

In the first step, the triethoxysilane derivative was allowed to react with surface ONa groups present on the $\mathrm{NaOH}$ treated titanium surfaces. Experiments have shown that this reaction proceeds satisfactorily only for Ti treated with alkaline solution and not with passivated or piranha treated Ti. Therefore any following experiments concerning PEI grafting were performed using only $\mathrm{NaOH}$ treated surfaces. Grafting of (3-chloropropyl)triethoxysilane on $\mathrm{Ti}$ was followed by hydrolysis of the ethoxy groups under ambient conditions leading to the formation of silanol groups which, upon increasing the temperature to $95^{\circ} \mathrm{C}$, either polycondensate via formation of $\mathrm{Si}-\mathrm{O}-\mathrm{Si}$ bonds [32] and, more importantly, form chemical bonds with the $-\mathrm{O}^{-} \mathrm{Na}^{+}$groups present on the titanium surface. As a result an organosilicon layer functionalized with chloropropyl moieties is produced that is chemically bonded to the titanium surface via $\mathrm{Ti}-\mathrm{O}-\mathrm{Si}$ bonds. The second step involves the Menshutkin reaction between the chloropropyl moieties of the organosilicon layer and the tertiary amines of PEI, leading to the formation of quaternary ammonium groups and the covalent attachment of the polymer on Ti surface.

At the final step calcium phosphate formation on PEI functionalized layer was realized by the addition over the PEI functionalized surfaces of $\mathrm{CaCl}_{2}$ and $\mathrm{Na}_{2} \mathrm{HPO}_{4}$ solutions to a final 10:6 Ca:P molar ratio. Hydrothermal treatment at $80^{\circ} \mathrm{C}$ for $16 \mathrm{~h}$, or at $130^{\circ} \mathrm{C}$ for $6 \mathrm{~h}$ in an autoclave was employed to affect the crystal morphology and particle size. The hydrothermal method usually affords materials with a high degree of crystallinity and has been employed, among others, in the synthesis of hydroxyapatite in the presence of amido, carboxylic or hydroxy terminated dendrimers [22-24] since it has been suggested that at room temperature the kinetically favorable but metastable OCP phase is preferably formed [33].

All the above steps were monitored employing FTIR, XPS and SEM/EDS analyses, the results of which are discussed in the following sections.

\subsubsection{FTIR analysis}

The FTIR spectra in the range $4,000-400 \mathrm{~cm}^{-1}$ of the final and the intermediate products are shown in Fig. 2. After the treatment with $\mathrm{NaOH}$, a variety of groups can be indentified proving its effect on $\mathrm{Ti}$ surface. The low intensity broad band in the 3,200-3,600 $\mathrm{cm}^{-1}$ region and the band centered at $1,625 \mathrm{~cm}^{-1}$ are assigned to $\mathrm{O}-\mathrm{H}$ stretching and deformation vibrations of weakly bound water giving evidence for the existence of $\mathrm{Ti}-\mathrm{OH}$ or $\mathrm{Ti}=\mathrm{O}$ groups [34]. The main characteristic absorption bands corresponding to the bending vibrations of the Ti-O groups (bands with maxima at 506 and $448 \mathrm{~cm}^{-1}$ ) [35] are merged into a broad peak centered at $\sim 480 \mathrm{~cm}^{-1}$. The shoulder at $878 \mathrm{~cm}^{-1}$ is characteristic of the $\mathrm{Na}-\mathrm{O}$ bending of the $\mathrm{Na}-\mathrm{O}-\mathrm{Ti}$ bond of sodium titanates $[35,36]$, whereas the very small peak at $1,061 \mathrm{~cm}^{-1}$ can be attributed to the respective bending vibration $\mathrm{H}-\mathrm{O}-\mathrm{Ti}$ of the hydrotitanates [35].

After the reaction of $\mathrm{Ti}$ coupons with (3-chloropropyl)triethoxysilane the formation of a chloropropyl siloxane polymer layer can be evidenced in the respective FTIR spectrum. Stretching and bending vibrations of the methylenes of the propyl moiety are clearly visible (Fig. 2), while the stretching vibrations of the trans and gauche configurations of the $\mathrm{C}-\mathrm{Cl}$ bond are present at 695 and $646 \mathrm{~cm}^{-1}$ respectively [37]. The formation of the siloxane

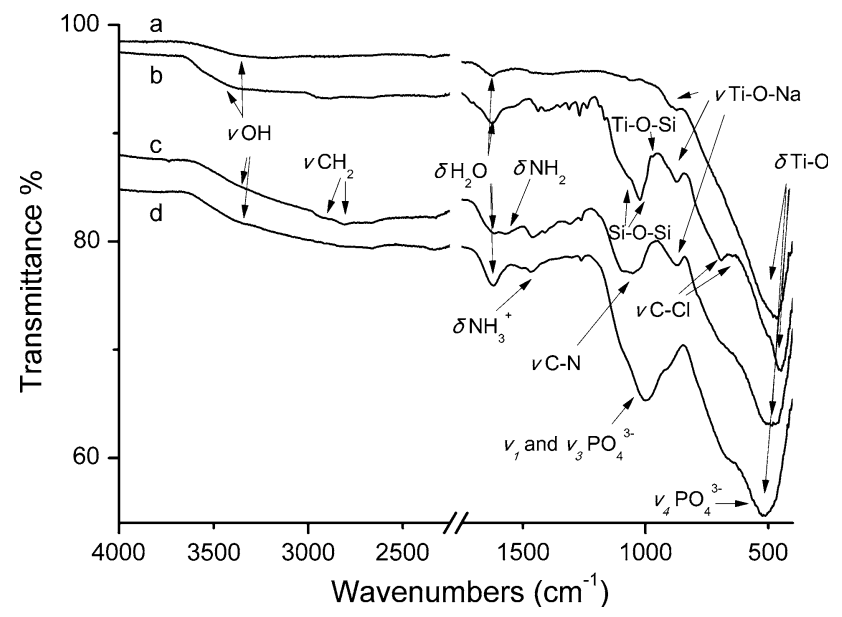

Fig. 2 FTIR spectra of Ti surface after: (a) chemical pretreatment with $\mathrm{NaOH}$, (b) silanization with (3-chloropropyl)triethoxysilane, (c) covalent attachment of PEI and (d) hydrothermal treatment at $130^{\circ} \mathrm{C}$ for calcium phosphate formation 
bridges is evident from the merged antisymmetric and symmetric stretching vibrations of the $\mathrm{Si}-\mathrm{O}-\mathrm{Si}$ bond $\left(1,021 \mathrm{~cm}^{-1}\right)$ and bending vibration $\left(793 \mathrm{~cm}^{-1}\right)$. A small peak present at $968 \mathrm{~cm}^{-1}$ indicates the presence of an amount of silanols. Although there is evidence for Ti-O-Si bond formation from the respective stretching vibration appearing as a small shoulder at $910 \mathrm{~cm}^{-1}[38,39]$, definitive proof for the chemical anchoring of the polymeric siloxane onto the titanium surface is given in the XPS analysis section below.

The covalent bonding of hyperbranched PEI to the above mentioned siloxane polymer layer via reaction of propyl chloride with tertiary amino groups is evidenced in the respective IR spectrum by the significant decrease of the intensity of the peaks at 695 and $646 \mathrm{~cm}^{-1}$ attributed to the stretching vibrations of the $\mathrm{C}-\mathrm{Cl}$ bond. In addition, the stretching band of $\mathrm{Si}-\mathrm{O}-\mathrm{Si}$ is overlaid by a broad peak $\left(1,100-1,020 \mathrm{~cm}^{-1}\right)$ attributed to the stretching vibration of C-N bonds of PEI's primary, secondary and tertiary amines. The symmetric and asymmetric $\mathrm{N}-\mathrm{H}$ bending modes of protonated quaternary $\left(\mathrm{NH}_{4}{ }^{+}\right)$and non protonated amino groups are also present at 1,469 and $1,512 \mathrm{~cm}^{-1}$.

The formation of calcium phosphate on PEI grafted $\mathrm{Ti}$ surfaces was also confirmed by IR spectroscopy. The respective bands of phosphate groups [40, 41] dominate the spectrum of the final organic-inorganic material covering almost completely the other peaks. The bands at $571 \mathrm{~cm}^{-1}$ and $614 \mathrm{~cm}^{-1}$ attributed to the excited $v_{4}$ mode of $\mathrm{PO}_{4}^{3-}$ groups ( $\mathrm{O}-\mathrm{P}-\mathrm{O}$ bending vibrations) is merged with the band of titanate at $480 \mathrm{~cm}^{-1}$ resulting in an apparent shift of the latter to $530 \mathrm{~cm}^{-1}$. The broad vibration bands due to the coupling effect of $v_{1}$ and $v_{3}$ stretching modes of $\mathrm{PO}_{4}{ }^{3-}$ are present at $920 \mathrm{~cm}^{-1}$ and $1,058 \mathrm{~cm}^{-1}$, respectively. The IR band assigned to deformation vibrations of absorbed $\mathrm{H}_{2} \mathrm{O}$ groups has been slightly shifted to $1,620 \mathrm{~cm}^{-1}$ probably due to the different environment of the absorbing material.

\subsubsection{XPS analysis}

XPS analysis confirmed that the surface of untreated $\mathrm{Ti}$ was covered by an oxide layer of a thickness less than $6.6 \mathrm{~nm}$ and a small amount of $\mathrm{OH}$ groups (Fig. 3a [sample 1]) in agreement with literature data which report the formation of a thin $\mathrm{TiO}_{2}$ layer of a thickness about $4 \mathrm{~nm}$ on $\mathrm{Ti}$ surface upon exposure to air [42, 43]. The oxide thickness was estimated by considering that for normal photoemission (zero angle of emission) the XPS analysis depth is estimated as $d=3 \lambda$, where $\lambda$ is the attenuation length of the photoelectron. Assuming that the Ti 2 p photoelectron is attenuated by a continuous $\mathrm{TiO}_{2}$ film, the $\lambda$ value was calculated to be $2.2 \mathrm{~nm}$ [44].

Upon $\mathrm{NaOH}$ treatment, the oxygen surface content has been increased from 53.5 at\% to 56.0 at\% and furthermore the Na content was 5.7 at\% in accordance with EDS results taking into consideration the very low depth of XPS analysis compared to EDS. Additionally, the $\mathrm{OH}^{-} / \mathrm{O}^{2-}$ ratio (Fig. 3a [sample 2]) decreased, whereas the absence of metallic $\mathrm{Ti}$ was attributed to the increased surface oxide layer thickness $(>6-7 \mathrm{~nm})$.

XPS survey spectra (Fig. 3b) after the first reaction step (treatment with (3-chloropropyl)triethoxysilane, Scheme 1) revealed, as expected, the presence of new species, i.e. $\mathrm{Cl}$ (5.9 at\%) and $\mathrm{Si}(10$ at\%). Further, $\mathrm{Na}$ was found substantially reduced $(0.9$ at $\%)$ in this case, whereas $\mathrm{C}$ was 39.6 at $\%$.

XPS O1 s spectra (Fig. 3a [sample 3]) after the first reaction step show two peaks at $530.8 \mathrm{eV}$ and $532.7 \mathrm{eV}$ that are attributed to the presence of $\mathrm{Ti}-\mathrm{O}-\mathrm{Si}$ and $\mathrm{Si}-\mathrm{O}-\mathrm{Si}$ bonds, respectively. The ratio of intensities of these peaks suggests strongest presence of the silicon oxygen bridges at the outmost surface. It is interesting to note that the peak at $530.8 \mathrm{eV}$ is slightly shifted at $0.3 \mathrm{eV}$ higher binding energy compared to the $\mathrm{NaOH}$ treated or untreated $\mathrm{Ti}$ coupons. Thus, this shift can be tentatively assigned to the formation of $\mathrm{Ti}-\mathrm{O}-\mathrm{Si}$ bonds at the expense of $\mathrm{Ti}-\mathrm{O}-\mathrm{Na}$ bonds.

The Ti $2 \mathrm{p}$ peak shifts marginally by $0.15 \mathrm{eV}$ to higher binding energy (Fig. 3c [sample 3]). Although this shift is close to the experimental error, $\pm 0.1 \mathrm{eV}$, it can also indicate that now $\mathrm{Ti}$ shares an $\mathrm{O}$ atom with $\mathrm{Si}$. Further, the $\mathrm{Cl}$ 2 p3/2 peak is observed at $200.3 \mathrm{eV}$, which corresponds to the presence of a chloropropyl moiety [45].

After the second reaction step (reaction of chloropropyl groups with PEI tertiary amino groups, Scheme 1), a further increase of carbon (45.9 at\%) as well as the appearance of $\mathrm{N}$ (13.5 at\%) was observed. The $\mathrm{N} 1 \mathrm{~s}$ shows its main peak at $399.3 \mathrm{eV}$ (peak $A$ in Fig. 3d) and a shoulder at the high binding energy site at about $400.8 \mathrm{eV}$ (peak $B$ in Fig. 3d) that corresponds to protonated quaternary amino groups. These groups correspond to $30 \%$ of the total nitrogen groups of PEI as determined by not shown peak fitting analysis. From the known ratio of primary:secondary:tertiary amino groups of PEI (1:1.15:1), one can easily deduce that the percentage of tertiary amino groups in PEI that can react with the chloropropyl groups affording quaternary groups is $31.5 \%$. Since $30 \%$ of the amino groups in the final product are quaternized, it is evident that the reaction has been driven almost into completion (conversion $\sim 95 \%$ ). Additionally, the $\mathrm{Cl} 2 \mathrm{p}_{3 / 2}$ main peak appears at about $197.5 \mathrm{eV}$ (the $2 \mathrm{p}_{1 / 2}$ of the doublet appears at $199 \mathrm{eV}$ ) indicating the presence of $\mathrm{Cl}^{-}$(Fig. 3e). Furthermore, the high binding energy component of the $\mathrm{Cl} 2 \mathrm{p}_{3 / 2}$ peak at $200.3 \mathrm{eV}$ (the equivalent $\mathrm{Cl} 2 \mathrm{p}_{1 / 2}$ appears at $201.8 \mathrm{eV}$ ) can be observed, indicating, after peak fitting analysis (not shown), that $60 \%$ of the chloropropyl groups were reacted with PEI. 
(a)

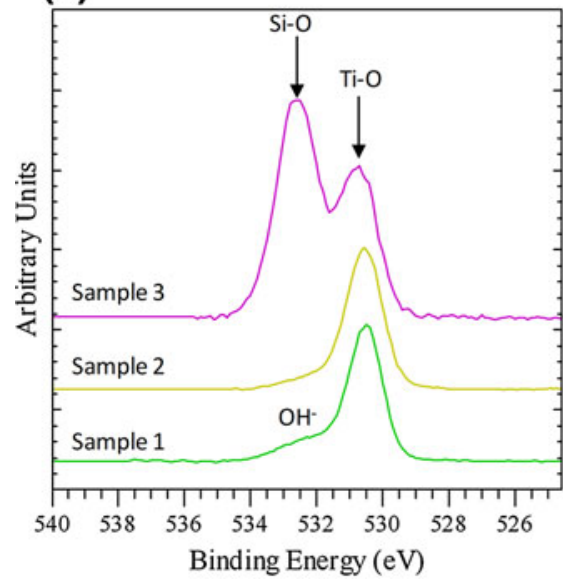

(d)

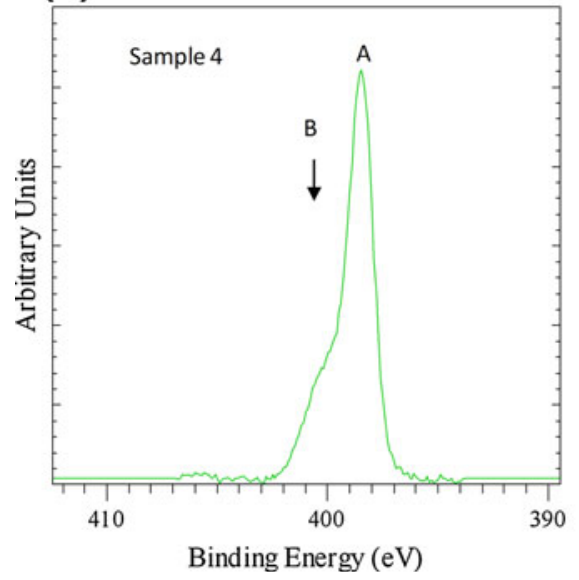

(b)

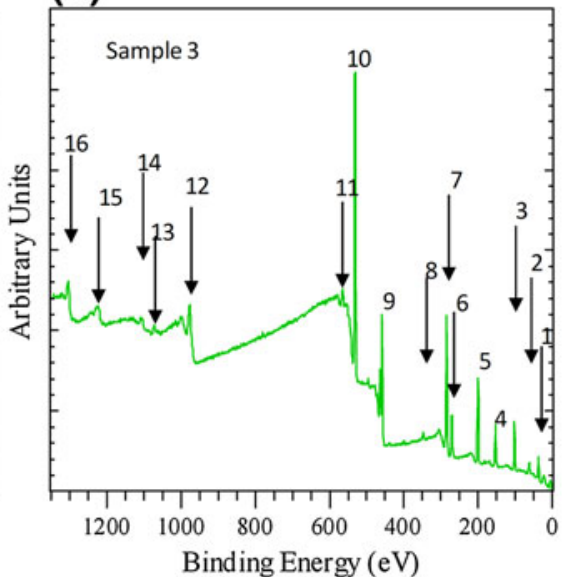

(e)

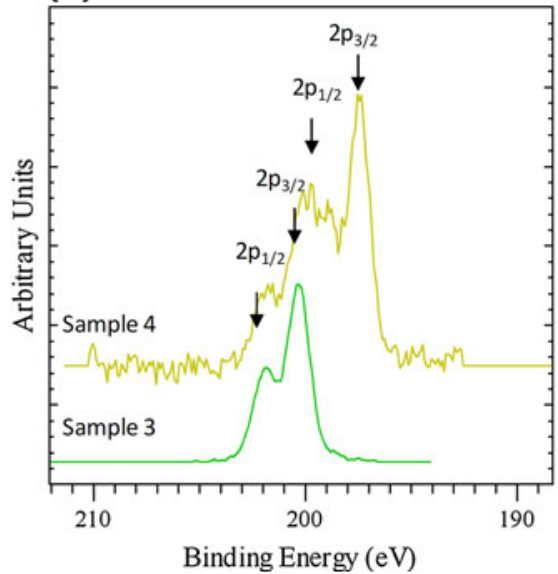

(c)

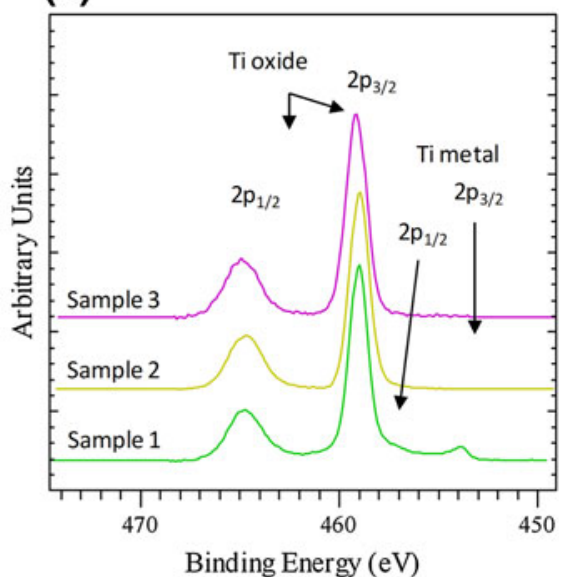

(f)

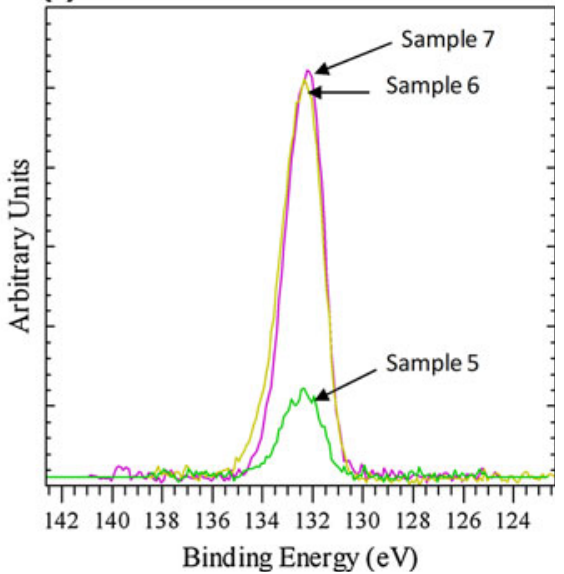

Fig. 3 XPS spectra (a): O1 s, (b) survey scan, (c) Ti2 $\mathrm{p}_{3 / 2}$, (d) N1 s, (e) $\mathrm{Cl} 2 \mathrm{p}$, (f) P2p. Sample 1: Ti untreated; Sample 2: $\mathrm{Ti} \mathrm{NaOH}$ pretreated; Samples 3 and 4: Ti after 1st reaction step and after 2nd reaction step (see scheme 1), respectively; Samples 5, 6 and 7: Ti coated with calcium phosphate formed at room temperature, after hydrothermal treatment at $80^{\circ} \mathrm{C}$ and after hydrothermal treatment at $130^{\circ} \mathrm{C}$, respectively. Peak labels at Fig 3b: 1: Ti 3p, 2: Ti 3 s, 3: Si 2p, 4: Si 2 s, 5: Cl 2p, 6: Cl 2 s, 7: C 1 s, 8: Ca 2p, 9: Ti 2p, 10: O 1 s, 11, Ti 2 s, 12: O KLL, 13: Ti $L M M$, 14: Ti $L M M$, 15: C KLL, 16: Cl $L M M$

\subsubsection{SEM/EDS analysis}

In agreement with FTIR and XPS analysis, SEM studies combined with EDS analysis confirmed that the active layer developed on $\mathrm{Ti}$ surface after its treatment with the alkaline solution is the basis for the production of very homogeneous coatings (Fig. 4a, b) with respect to the polymeric layer as well as the calcium phosphate layer produced hydrothermally (at 130 or $80^{\circ} \mathrm{C}$ ). EDS analysis revealed the presence of $\mathrm{Si}, \mathrm{Cl}$ and $\mathrm{C}$ atoms in addition to $\mathrm{Na}$, $\mathrm{Ti}$ and $\mathrm{O}$ in the first case (Fig. 4c) and, additionally, $\mathrm{Ca}$ and $\mathrm{P}$ atoms in the latter case (Fig. 4d). The atomic ratio of $\mathrm{Ca} / \mathrm{Ti}$ in the final phosphate coating was found to be ca. 0.5 in full agreement with XPS studies. 
(a)

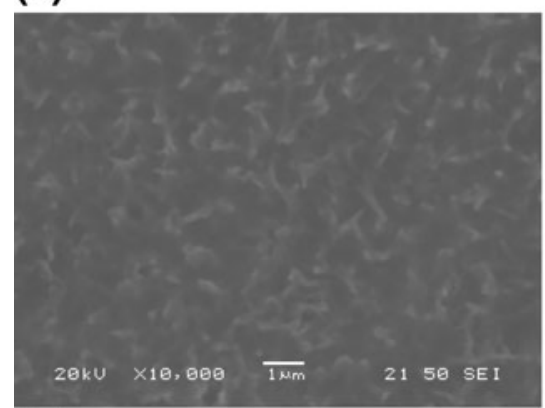

(c)

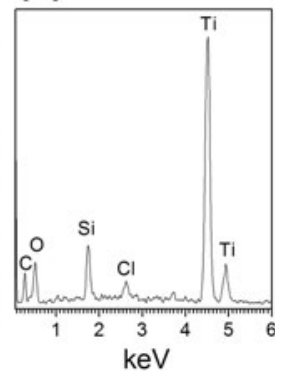

(b)

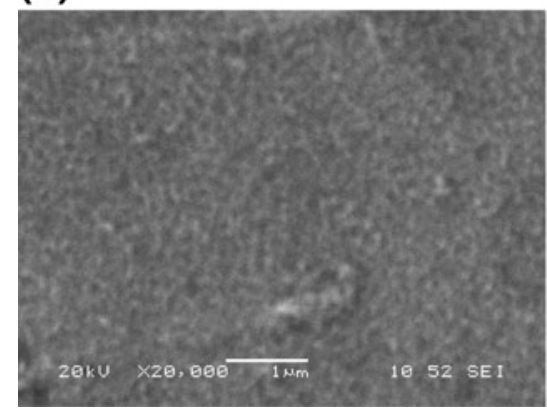

(d)

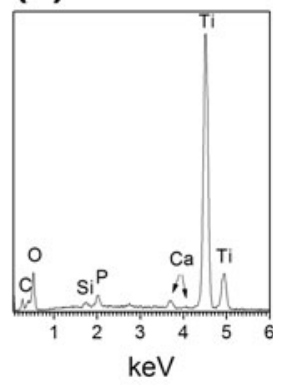

Fig. 4 SEM secondary electron images (a and $\mathbf{b}$ ) and respective EDS analysis (c and d) of $\mathrm{Ti}$ surface fine polished and chemically pretreated with $\mathrm{NaOH} 5 \mathrm{M}$ : (a) and (c) after surface silanization and PEI covalent attachment; (b) and (d) after coating with calcium phosphate and hydrothermal treatment at $130^{\circ} \mathrm{C}$

\subsection{Bioactivity studies in SBF}

The bioactivity of surface modified Ti coupons, through the coating procedures developed, was studied by evaluating, employing SEM/EDS and XRD analyses, the hydroxyapatite evolution in SBF for a period of up to 28 days. The study compared the effect of the different parameters of the methodology adopted on calcium phosphate formation and specifically the hydrothermal treatment temperature employed for calcium phosphate formation on PEI functionalized Ti surfaces and the level of Ti surface polishing. Additionally, the comparison study comprised uncoated samples treated with $\mathrm{NaOH}$ and samples after surface silanization and PEI covalent attachment.

The XRD spectra of Ti coupons coated with calcium phosphate after hydrothermal treatment at $80^{\circ} \mathrm{C}$ following their immersion in SBF for various time periods are shown in Fig. 5. In general, XRD analysis showed that, irrespectively of the coating parameters, the hydroxyapatite main characteristic peaks (JCPDS 9-432) appear in all samples after some immersion period in SBF. The characteristic Ti peaks (JCPDS 44-1294) of the substrate are also present in all diffractograms. However, as the immersion time in SBF is prolonged, the intensity of Ti peaks is reduced whereas that of hydroxyapatite peaks is increased continuously (Fig. 5a) denoting the progressive evolution of hydroxyapatite layer
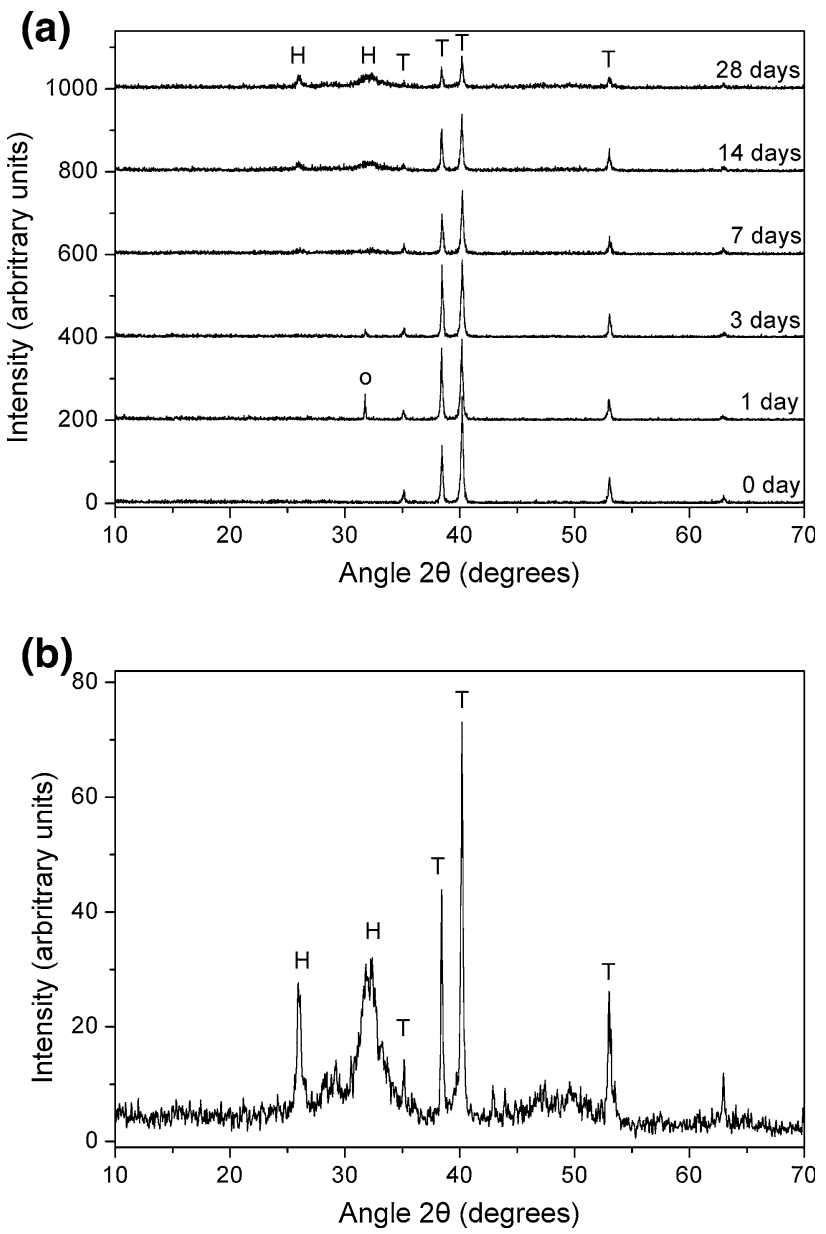

Fig. 5 a XRD patterns after $0,1,3,7,14$ and 28 days immersion in SBF; $\mathbf{b}$ detail of the 28 days immersion XRD pattern. Ti coupons were coated with calcium phosphate and hydrothermally treated at $80^{\circ} \mathrm{C}$. ( $H$ hydroxyapatite, $\left.T \mathrm{Ti}, o \mathrm{NaCl}\right)$

on the surface. This behaviour is similar in all the cases examined, although differences in peaks intensity for the same immersion time can be noticed among the various samples. In fact, the main hydroxyapatite peak can be detected after 7 days in SBF and is prominent after the 28 days immersion period (Fig. 5b) when the thickness of the hydroxyapatite layer has reached 10-15 $\mu \mathrm{m}$ (Fig. 6 and Table 2) depending on the case under evaluation.

SEM combined with EDS studies are in agreement with the XRD analysis revealing the progressive evolution of calcium phosphate phase on Ti after immersion in SBF. For the fine polished samples coated with calcium phosphate after hydrothermal treatment at $130^{\circ} \mathrm{C}$, spherical calcium phosphate particles (in the nm scale) spread all around the surface area can be easily observed even after an immersion period of only $24 \mathrm{~h}$ (Fig. 7a). This layer develops continuously and after 7 days of immersion fully covers the surface consisting of spherical agglomerates of a mean diameter of $2-3 \mu \mathrm{m}$ (Fig. 7c). After this initial period, the 


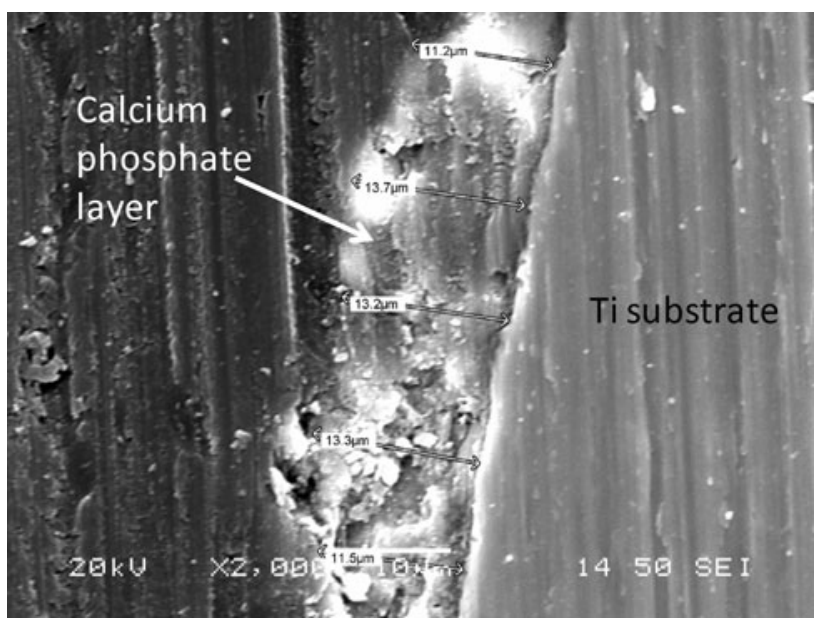

Fig. 6 Cross section under SEM of calcium phosphate layer after immersion in SBF for 28 days (polished sample coated with calcium phosphate after hydrothermal treatment at $80^{\circ} \mathrm{C}$ )

evolution is continuous with regard to both the thickness of the layer formed (Table 2) and the size of spherical agglomerates (Fig. 7d, e). The $\mathrm{Ca} / \mathrm{P}$ molar ratio measured by EDS analysis on these calcium phosphate layers is also increased from 0.5 , which was measured immediately after the hydrothermal treatment, to a value of ca. 1 after 3 days immersion. The ratio continuously increases to ca. 1.2 after 5 days and to ca. 1.5 after 7 days, whereas after 14 days in SBF the ratio determined was ca. 1.65 indicating the complete formation of hydroxyapatite. These results are in good agreement with Zang et al. [48] who report a similar evolution behaviour for the calcium phosphate formed in SBF upon a copolymer coating covering the Ti surface.

The temperature of hydrothermal treatment does not considerably affect the calcium phosphate evolution rate in SBF as the measurement of the layer thickness reveals (Fig. 6, Table 2). Indeed, the examination under SEM of samples' cross sections was in agreement with XRD analysis confirming a progressive evolution of calcium phosphate layer deposited during immersion in SBF (Table 2). The thickness of this layer became measurable after 7 days when it reached $1-5 \mu \mathrm{m}$ and continued increasing with a rate depending on sample case. The $\mathrm{Ca} / \mathrm{P}$ molar ratio evolution also shows the same behavior as in the previous case. However, for the same immersion time, a finer microstructure of the deposited layer can be observed when hydrothermal treatment was performed at $80^{\circ} \mathrm{C}$ (Fig. 7f) compared to the layer formed after hydrothermal treatment at $130^{\circ} \mathrm{C}$ (Fig. $7 \mathrm{c}$ ).

Ti surface roughness (Table 1) was the second parameter examined for its effect on Ti surface bioactivity. At a first stage, surface roughness proved affecting the homogeneity of the hydrothermally treated calcium phosphate layer. In case of fine polishing, a very thin and homogeneous calcium phosphate layer was deposited (Fig. 4b). As the polishing level was gradually reduced the surface coverage by calcium phosphate was decreased considerably. It should be noted that the deposited material formed scarcely dispersed agglomerates apparently due to preferred nucleation at edge points. The initial, reduced, homogeneity of calcium phosphate layer that was developed on rough surfaces after hydrothermal treatment, affected also the homogeneity of the calcium phosphate layer formed, at a second stage, in SBF and consequently its bioactivity. The more homogeneous initial coatings deposited on the fine polished surfaces lead in turn to a more homogeneous evolution of calcium phosphate in SBF resulting finally in apatite layers of uniform and greater mean thickness (Table 2). However, the final microstructure obtained is similar with that on top of fine polished samples.

For comparison purposes, fine polished $\mathrm{Ti}$ samples chemically pretreated with $\mathrm{NaOH}$ without any further coating, or samples having only the PEI layer covalently attached, were immersed in SBF and evaluated in terms of their bioactivity. In both cases, a calcium phosphate layer of similar morphology (Fig. 8) to that already described was developed over time but with a lower evolution rate as revealed by both the surface morphology examination and layer thickness measurements. This evolution rate was significantly reduced in the case of $\mathrm{NaOH}$ treated coupons,
Table 2 Calcium phosphate layer evolution in SBF

\begin{tabular}{|c|c|c|c|c|c|}
\hline \multirow[t]{2}{*}{ Sample } & \multirow{2}{*}{$\begin{array}{l}\text { Hydrothermal } \\
\text { treatment } \\
\text { temperature } \\
\left({ }^{\circ} \mathrm{C}\right)\end{array}$} & \multirow[t]{2}{*}{ Polishing level } & \multicolumn{3}{|c|}{$\begin{array}{l}\text { Thickness of calcium phosphate } \\
\text { layer after immersion in SBF }(\mu \mathrm{m})\end{array}$} \\
\hline & & & $\begin{array}{l}7 \text { days } \\
\text { immersion }\end{array}$ & $\begin{array}{l}14 \text { days } \\
\text { immersion }\end{array}$ & $\begin{array}{l}28 \text { days } \\
\text { immersion }\end{array}$ \\
\hline \multirow[t]{4}{*}{ Calcium phosphate coated } & 130 & Fine polished & $5.5 \pm 0.5$ & $8.5 \pm 0.9$ & $14.3 \pm 1.0$ \\
\hline & 80 & Fine polished & $5.3 \pm 0.5$ & $7.5 \pm 0.8$ & $13.0 \pm 1.0$ \\
\hline & 130 & Polished up to 1000 grit & $2.7 \pm 0.5$ & $5.5 \pm 1.0$ & $11.7 \pm 1.2$ \\
\hline & 130 & Unpolished & $1.5 \pm 0.4$ & $4.0 \pm 1.3$ & $10.7 \pm 1.6$ \\
\hline PEI coated & - & Fine polished & $5.0 \pm 0.5$ & $6.8 \pm 0.7$ & $10.6 \pm 0.9$ \\
\hline $\mathrm{NaOH}$ treated & - & Fine polished & $1.3 \pm 0.1$ & $1.7 \pm 0.4$ & $7.0 \pm 0.9$ \\
\hline
\end{tabular}


(a)

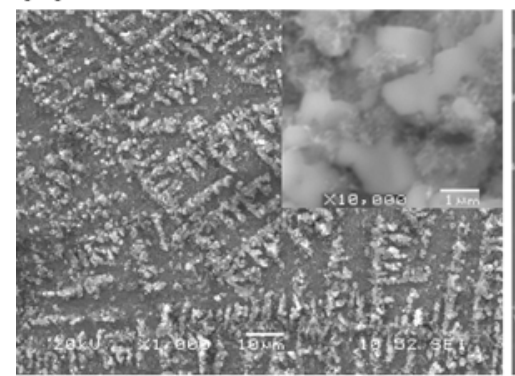

(d)

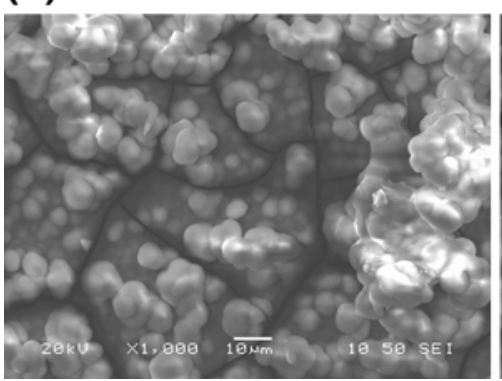

(b)

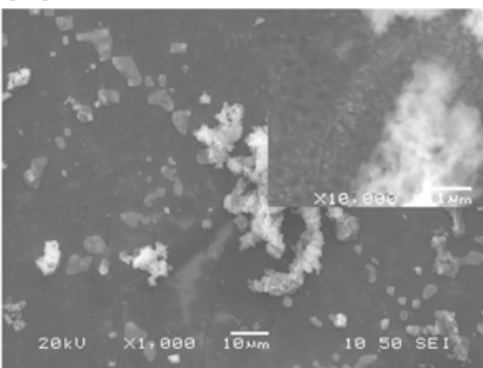

(e)

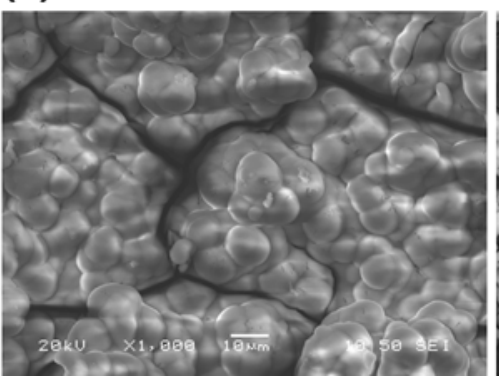

(c)

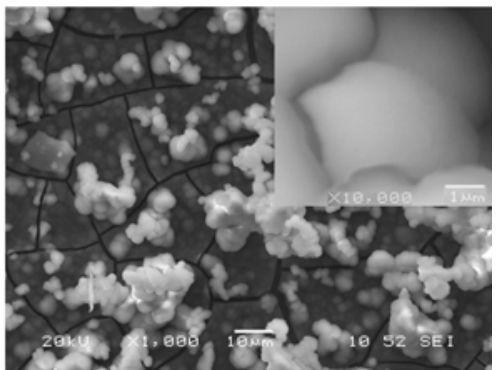

(f)

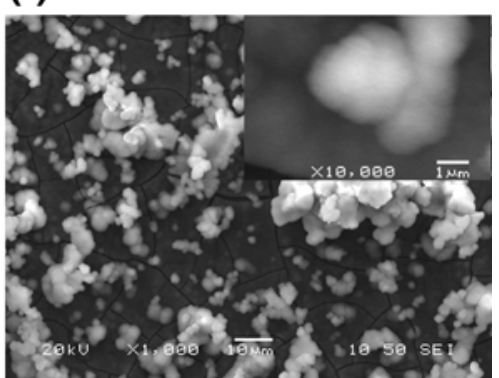

Fig. 7 SEM secondary electron images of deposited calcium phosphate layer after immersion in SBF: a-e fine polished samples, chemically treated with $\mathrm{NaOH}$ and coated with the PEI and the calcium phosphate layer after hydrothermal treatment at $130^{\circ} \mathrm{C}$

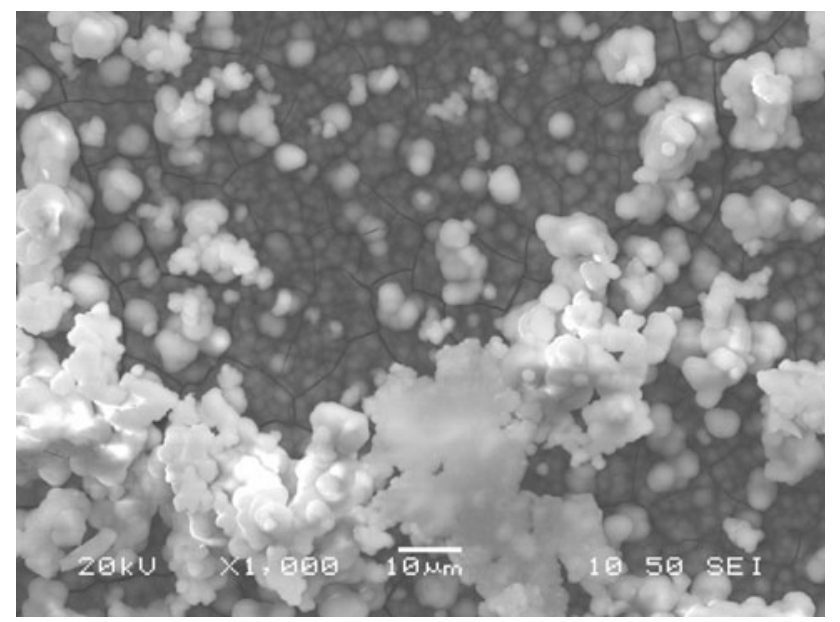

Fig. 8 SEM secondary electron images of calcium phosphate surface layer on fine polished, $\mathrm{NaOH}$ pretreated and PEI coated Ti sample after immersion in SBF for 7 days

but it was quite high when the surface was covered with the PEI layer (Table 2) demonstrating that this layer possesses by itself a very good bioactivity. The accelerated hydroxyapatite formation rate when $\mathrm{Ti}$ is covered with PEI compared to the respective rate of chemically pretreated only Ti, exemplifies the role of PEI in the process, which interacts electrostatically with growing calcium phosphate crystals modifying at the same time the interfacial properties of Ti. In this way, PEI can be considered as playing a immersed in SBF for: a 1, b 5, c 7, d 14 and e 28 days; $\mathbf{f}$ fine polished sample bearing a calcium phosphate coating hydrothermally treated at $80^{\circ} \mathrm{C}$ immersed in SBF for 7 days. (Images of higher magnification in inserts)

role analogous to that of proteins in the biogenesis of hydroxyapatite contributing to its biomimetic synthesis in this case. This could also lead to the conclusion that the additional step of calcium phosphate coating employing hydrothermal treatment at elevated temperatures could be avoided. However, if such surface functionalized materials are going to be utilized as implants in practice, this step is necessary in order to provide, from the very beginning of its application, a biocompatible, osteoconductive and non-immunogenic surface.

\section{Conclusions}

A hybrid bioactive titanium coating was developed employing a methodology based on covalently attaching, through an intermediate surface silanization step, a hyperbranched poly(ethylene imine) layer on $\mathrm{NaOH}$ treated Ti coupons. Further, the deposition of calcium phosphate layer was carried out using a hydrothermal method at two different temperatures. The bioactivity of the modified $\mathrm{Ti}$ surfaces was assessed by following the formation of calcium phosphate in $\mathrm{SBF}$ at $37^{\circ} \mathrm{C}$. Poly(ethylene imine) coated $\mathrm{Ti}$ surfaces demonstrated very good bioactivity in SBF accelerating calcium phosphate deposition compared to controls (untreated or only alkali treated surfaces). Almost equally good results were obtained for surfaces bearing the additional calcium phosphate layer after 
hydrothermal treatment. However, alkali treatment and surface polishing are also critical steps since they facilitate the covalent bonding of the polymeric layer and affect the homogeneity of the final deposited HAP layer, respectively.

Open Access This article is distributed under the terms of the Creative Commons Attribution Noncommercial License which permits any noncommercial use, distribution, and reproduction in any medium, provided the original author(s) and source are credited.

\section{References}

1. Xiao S-J, Textor M, Spencer ND, Sigrist H. Covalent attachment of cell-adhesive, (Arg-Gly-Asp)-containing peptides to titanium surfaces. Langmuir. 1998;14:5507-16.

2. van Noort R. Titanium: the implant material of today. J Mater Sci. 1987;22:3801-11.

3. Cameron HU. 6-Year results with a microporous-coated metal hip-prosthesis. Clin Orthop Relat Res. 1986;208:81-3.

4. Doherty PJ, Williams DF. Biomaterial-tissue interfaces: advances in biomaterials. Vol 10. New York: Elsevier; 1992.

5. Jonášová L, Muller FA, Helebrannt A, Strnad J, Greil P. Biomimetic apatite formation on chemically treated titanium. Biomaterials. 2004;25:1187-94.

6. Nishiguchi S, Nakamura T, Kobayashi M, Miyaji F, Kokubo T. The effect of heat treatment on bone-bonding ability of alkalitreated titanium. Biomaterials. 1999;20:491-500.

7. Hench LL. Bioceramics. J Am Ceram Soc. 1998;81:1705-27.

8. Thomas KA. Hydroxyapatite coatings. Orthopedics. 1994;17: 267-78.

9. Radin SR, Ducheyne P. Plasma spraying induced changes of calcium phosphate ceramic characteristics and the effect on in vitro stability. J Mater Sci: Mater Med. 1992;3:33-42.

10. Shibli SMA, Mathai S. The role of calcium gluconate in electrochemical activation of titanium for biomimetic coating of calcium phosphate. J Biomed Mater Res A. 2008;87:994-1002.

11. Blackwood DJ, Seah KHW. Influence of anodization on the adhesion of calcium phosphate coatings on titanium substrates. J Biomed Mater Res A. 2010;93:1551-6.

12. Jarcho M, Kay JF, Gumaer RH, Drobeck HP. Tissue, cellular and subcellular events at a bone-ceramic hydroxyapatite interface. J Bioeng. 1977;1:79-92.

13. Kokubo T. Surface chemistry of bioactive glass-ceramics. J NonCryst Solids. 1990;120:138-51.

14. Hench LL. Bioceramics: from concept to clinic. J Am Ceram Soc. 1991;74:1487-510.

15. Wanga CX, Wanga M, Zhoub X. Nucleation and growth of apatite on chemically treated titanium alloy: an electrochemical impedance spectroscopy study. Biomaterials. 2003;24:3069-77.

16. Gonzalez McQuire R, Tsetsekou A. Hydroxyapatite-biomolecule coatings onto titanium surfaces. Surf Coat Tech. 2008;203(1-2): 186-90.

17. Walsh D, Kingston JL, Heywood BR, Mann S. Influence of monosaccharides and related molecules on the morphology of hydroxyapatite. J Cryst Growth. 1993;133:1-12.

18. Bertoni E, Bigi A, Falini G, Panzavolta S, Roveri N. Hydroxyapatite/polyacrylic acid nanocrystals. J Mater Chem. 1999;9: 779-82.

19. Li J, Chen Y, Yin Y, Yao F, Yao K. Modulation of nanohydroxyapatite size via formation on chitosan-gelatin network film in situ. Biomaterials. 2007;28:781-90.
20. Donners JJJM, Nolte RJM, Sommerdijk NAJM. Dendrimer-based hydroxyapatite composites with remarkable materials properties. Adv Mater. 2003;15:313-6.

21. Khopade AJ, Khopade S, Jain NK. Development of hemoglobin aquasomes from spherical hydroxyapatite cores precipitated in the presence of half-generation poly(amidoamine) dendrimer. Int J Pharmaceutics. 2002;241:145-54.

22. Zhang F, Zhou Z-H, Yang S-P, Mao L-H, Chen H-M, Yu X-B. Hydrothermal synthesis of hydroxyapatite nanorods in the presence of anionic starburst dendrimer. Mater Lett. 2005;59:1422-5.

23. Yan S-J, Zhou Z-H, Zhang F, Yang S-P, Yang L-Z, Yu X-B. Effect of anionic PAMAM with amido groups starburst dendrimers on the crystallization of $\mathrm{Ca}_{10}\left(\mathrm{PO}_{4}\right)_{6}(\mathrm{OH})_{2}$ by hydrothermal method. Mater Chem Phys. 2006;99:164-9.

24. Zhou Z-H, Zhou P-L, Yang S-P, Yu X-B, Yang L-Z. Controllable synthesis of hydroxyapatite nanocrystals via a dendrimer-assisted hydrothermal process. Mater Res Bull. 2007;42:1611-8.

25. Oliveira JM, Sousa RA, Kotobuki N, Tadokoro M, Hirose M, Mano JF, Reis RL, Ohgushi H. The osteogenic differentiation of rat bone marrow stromal cells cultured with dexamethasoneloaded carboxymethylchitosan/poly(amidoamine) dendrimer nanoparticles. Biomaterials. 2009;30:804-13.

26. Tomalia DA. Birth of a new macromolecular architecture: dendrimers as quantized building blocks for nanoscale synthetic polymer chemistry. Prog Polym Sci. 2005;30:294-324.

27. Martin HJ, Schulz KH, Bumgardner JD, Walters KB. XPS study on the use of 3-aminopropyltriethoxysilane to bond chitosan to a titanium surface. Langmuir. 2007;23:6645-51.

28. Rakngarm A, Miyashita Y, Mutoh Y. Formation of hydroxyapatite layer on bioactive $\mathrm{Ti}$ and $\mathrm{Ti}-6 \mathrm{Al}-4 \mathrm{~V}$ by simple chemical technique. J Mater Sci Mater Med. 2008;19:1953-61.

29. Moulder JF, Stickle WF, Sobol PE, KD Bomben. Handbook of X-ray photoelectron spectroscopy. Eden Prairie, MN: PerkinElmer Corporation; 1992.

30. Beamson G, Briggs D. High resolution XPS of organic polymers. London: John Wiley \& Sons; 1992.

31. Jalota S, Bhaduri SB, Tas AC. Effect of carbonate content and buffer type on calcium phosphate formation in SBF solutions. J Mater Sci: Mater Med. 2006;17:697-707.

32. Arkas M, Tsiourvas D, Paleos CM. Organosilicon dendritic networks in porous ceramics for water purification. Chem Mater. 2005; 17:3439-44.

33. Viswanath B, Ravishankar N. Controlled synthesis of plateshaped hydroxyapatite and implications for the morphology of the apatite phase in bone. Biomaterials. 2008;29:4855-63.

34. Wei M, Kim HM, Kokubo T, Evans JH. Optimising the bioactivity of alkaline-treated titanium alloy. Mater Sci Eng C. 2002; 20:125-34

35. Bobrova AM, Zhigun IG, Bragina MI, Fotiev AA. Infrared absorption spectra of various titanium compounds. J Appl Spectrosc. 1972;8:59-63.

36. Janakirama Rao BhV. Properties and structure of glasses in the binary systems alkali-TiO 2 . J Am Ceram Soc. 1964;47:455-63.

37. Bellamy LJ. The infrared spectra of complex molecules. London: Chapman and Hall; 1975. 16 p.

38. Matsuura $\mathrm{Y}$, Kumon $\mathrm{K}$, Tohge $\mathrm{N}$, Inoue $\mathrm{H}$, Matsukawa $\mathrm{K}$. Fabrication of polysilane-titania hybrid thin films. Thin Solid Films. 2002;422:4-7.

39. Gu C, Zhang Z, Dang H. Preparation and characterization of hydrophobic organic-inorganic composite thin films of PMMA/ $\mathrm{SiO}_{2} / \mathrm{TiO}_{2}$ with low friction coefficient. Appl Surf Sci. 2004; 221:129-35.

40. Shi J, Ding C, Wu Y. Biomimetic apatite layers on plasmasprayed titanium coatings after surface modification. Surf Coat Technol. 2001;137:97-103. 
41. Bahadur KCR, Kim CK, Khil MS, Kim HY, Kim IS. Synthesis of hydroxyapatite crystals using titanium oxide electrospun nanofibers. Mater Sci Eng C. 2008;28:70-4.

42. Xie Y, Liu X, Chu PK, Ding C. Nucleation and growth of calcium-phosphate on Ca-implanted titanium surface. Surf Sci. 2006;600:651-6.

43. Healey KE, Ducheyne P. Hydration and preferential molecular adsorption on titanium in vitro. Biomaterials. 1992;13:553-61.

44. Powell CJ, Jablonski A. NIST electron inelastic-mean-free-path database 71, National Institute of Standards and Technology, 2000.

45. Wagner CD, Naumkin AV, Kraut-Vass A, Allison JW, Powell CJ, Rumble Jr. JR. Compilation and evaluation: NIST x-ray photoelectron spectroscopy database-IST standard reference database 20 version 3.4 (Web Version); 2003. http://srdata. nist.gov/xps/.

46. Eliaz N, Kopelovitch W, Burstein L, Kobayashi E, Hanawa T. Electrochemical processes of nucleation and growth of calcium phosphate on titanium supported by real-time quartz crystal microbalance measurements and X-ray photoelectron spectroscopy analysis. J Biomed Mater Res A. 2009;89:270-80.

47. Dorozhkin SV, Epple M. Biological and medical significance of calcium phosphates. Angew Chem Int Ed. 2002;41:3130-46.

48. Zhang C, Li Z-A, Cheng X-R, Xiao Q, Li H-B. Hydroxyapatite crystals biologically inspired on titanium by using an organic template based on the copolymer of acrylic acid and itaconic acid. J Biomed Mater Res A. 2010;92:63-9. 